\title{
Guidelines for Designing a Smart and Ubiquitous Learning Environment with Respect to Cultural Heritage
}

\author{
Alaa Alkhafaji ${ }^{1}$, Sanaz Fallahkhair ${ }^{2}$, Mihaela Cocea ${ }^{1}$ and Jonathan Crellin ${ }^{1}$ \\ ${ }^{1}$ School of Computing, University of Portsmouth, Buckingham Building, Portsmouth, UK \\ \{alaa.alkhafaji,mihaela.cocea,jonathan.crellin\}@port.ac.uk \\ ${ }^{2}$ School of Computing, University of Brighton, Lewes Road, Brighton UK \\ S.Fallahkhair@brighton.ac.uk
}

\begin{abstract}
This paper introduces a list of guidelines for designing mobile location-based learning services with respect to cultural heritage sites. This list was set out based on the results of a userstudy in the field. The user study was carried out with adult endusers to evaluate a prototype mobile application that delivered information through mobile phones and smart eye glasses simultaneously regarding cultural heritage sites based on location. Augmented reality and location-based services are utilised in this app.
\end{abstract}

Keywords-Usability evaluation; Location-based services; Mobile and wearable technologies

\section{INTRODUCTION}

The emerging of mobile learning and wearable computing offers a prospect for people to take a learning opportunity whenever they want regardless of time and place [1]. Providing services that assist people learning while they are doing their daily routine would help enhance informal learning which supports people to be in charge of their learning without concern about affording the time. Additionally, using Location-Based Services (LBS) to deliver information based on people's physical location could have a good impact on supporting access to information regarding the current contexts on-the-move [2]. That in turn supports the concept of ubiquitous learning [3].

LBS technology has already been used to support learning onthe-move in different domains including cultural heritage [4, 5]. Introducing useful and effective services to be used at cultural heritage sites could enhance learning from those sites. That in turn, helps drawing the authorities' attention towards sites, which subsequently helps in preserving them [6].

User acceptance is a key factor of measuring effectiveness and usefulness of new technologies [7]. The user-centred design approach, which is being used in this study, has been widely used to address user requirements [8]. With the mobile learning, learners interact with the contexts and with each other via interfaces of mobile devices. Therefore, it becomes essential to take good care when designing such services in terms of interaction design. This paper presents a user study to evaluate the SmartCiy prototype; a smart and ubiquitous learning environment of mobile location-based services to be used at outdoor cultural heritage sites. SmartCity was evaluated in the field by adult end-user to examine aspects of usability, usefulness and acceptance. Smart eye glasses were used in this research to explore the potential of harnessing them in such services. The results of the evaluation helped in shaping a framework for designing such services and in turn, enhancing the first version of guidelines that have been set out in a previous study [9].

\section{RELATED WORK}

Mobile technology has been increasingly utilised to support user experience in cultural heritage context. Augmented Reality technology (AR) recently has been utilised in cultural heritage context to enhance visitors' experiences. Some projects have been designed for indoors cultural heritage sites, and also evaluated in museums [10], [11], [12]. Archeoguide [13] utilises $\mathrm{AR}$ for ruined sites to help visitors visualise the site. Takacs et al. [14] have utilised AR for outdoors cultural heritage setting based on mobile devices. LBS also have been employed in cultural heritage contexts. Candello [4] has proposed a number of guidelines for outdoors mobile guide, which utilises LBS. Van Aart, Wielinga and Van Hage [5] have studied the use of GPS in cultural heritage settings. The authors used the user's physical location that is determined by the GPS receiver to retrieve historical information about the surrounding environment. Suh, Shin, Woo, Dow and MacIntyre [15] proposed a system to track visitors' routs and enable them to share their experiences as a group while they are on a trip.

As it has been shown in this section, a significant attention has been paid by the literature to investigate the potential of mobile location-based and AR apps. However, there are few studies that have considered the outdoors setting of cultural heritage and proposed guidelines for designing such services. This study proposes a list of guidelines for designing a smart learning environment for outdoor cultural heritage sites based on mobile and wearable computing utilising LBS and AR technologies. 


\section{The EVALUATION STUDY}

A prototype app with a context aware service is introduced for outdoor cultural heritage settings; SmartCity. The app was developed based on requirements that resulted from a field study, which was further analysed to draw out the first version of the guidelines [9]. The requirements translated into features and services included: a) location-based notification; b) multimode information format; c) see sites how appeared in the past. This app uses LBS to identify visitors' location, which in turn, allows the device to provide instant information about nearby cultural heritage sites using mobile and wearable technologies. Smart eye glasses were used in this research to deliver notification simultaneously with the mobile device. AR technology was used to show how sites used to be in the past; an old image that shows how an attraction appeared in the past attached to a live camera view when facing the attraction (see Fig. 1).

The evaluation study was carried out in order to obtain users' feedback regarding their experience in using the app which in turn helps to capture usability issues. That in turn, reinforces the enhancement of the framework of mobile location-based learning services and enhancing the guidelines.

\section{A. Methods}

A combination of three methods was used which includes: questionnaire, observation and a brief group interview. The convenience sampling method was used to recruite participants via emails and social media. A permission to use the Historic Dockyard as a proof-of-concept has been obtained from the authorities of the site. Participants were given android devices which contained the application and a sheet containing a description of how the app works. They were asked to use the app while they were walking around the site. The study was carried out in four sessions which took place between 10 and 12 October 2016; each session lasted around 2 hours; the tour and the discussion took around one hour each.

This study used a questionnaire technique with a combination of different types of questions: scale of five, closed questions of two choices (yes/no) and open ended questions. The questionnaire involves three sections: usability evaluation, features rating, and overall acceptance. SPSS was used to analyse the quantitative data that was obtained from the questionnaire.

The usability section consists of six categories that were adopted from the ISO metric questionnaire [16]. The categories include: suitability for learning, self-descriptiveness, controllability, conformity with user expectations, error tolerance, and learnability. Each category involves a set of statements that participants were asked to state to what extend they agree or disagree with. A likert scale of five was used, where $1=$ predominantly disagree and $5=$ predominantly agree. Moreover, participants were given an opportunity to indicate 'No opinion' to prevent a random selection which was treated as missing data in the analysis. This study also gathered users' feedback regarding the app's features in order to assess how useful these features were to users in their learning's journey. Participants were asked to rate a number of features of the app on a scale of five giving that $1=$ useless and $5=$ useful. Furthermore, participants were asked regarding their overall attitude towards this app.

A brief group interview was held with participants after filling the questionnaire to obtain in-depth opinions regarding their experience in using the app in the field. Participants were asked about their experience using the app and also to point out any challenges that they had, if any. In addition, they were asked if there are any suggestions they would like to give to make the app better.

The observational study was carried out in order to capture any problems or difficulties users might experience when using the app. Notes were taking during the tour by the researcher as the authorities of the site did not allow filming the tour due to security issues as the site is a navalbase.

\section{B. Participants}

26 participants with age ranged between 20 and 71 took part in this study; they were 18 males and 8 females from different nationalities; Iraq, Britain, Germany, Iran, Sweden, Libya, Nigeria, Senegal, Jordan and Colombia. Their occupations were: 19 students (undergraduate, master and $\mathrm{PhD}$ ), one engineer, one project manager, one unemployed, one teaching fellow and three retired.

\section{The results}

The evaluation study with potential users was carried out in order to highlight the weak and strong points of the app from the user's perspective. The results of the three techniques are outlined below.

The results of the usability questionnaire show that participants reacted positively regarding the usability aspects of the app. The average of each category is ranged between 3.06 and 4.25 which indicates participants found it easy to use (see Table I).

TABLE I. THE USABILITY RESULTS

\begin{tabular}{|l|c|}
\hline \multicolumn{1}{|c|}{ The category } & The average \\
\hline Suitability for learning & 3.94 \\
\hline Self-descriptiveness & 4.05 \\
\hline Controllability & 3.71 \\
\hline Conformity with user expectations & 3.84 \\
\hline Error tolerance & 3.06 \\
\hline Learnability & 4.25 \\
\hline
\end{tabular}




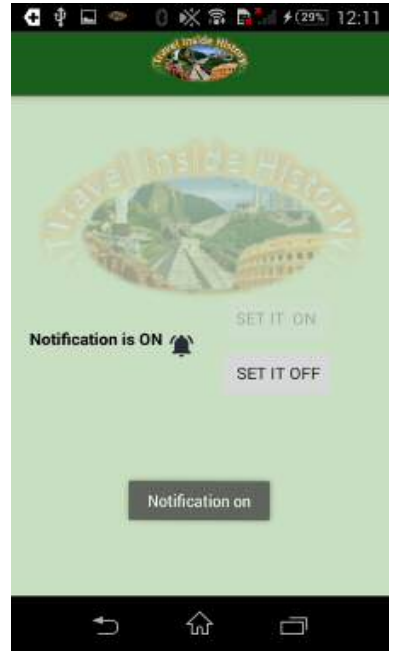

The main page

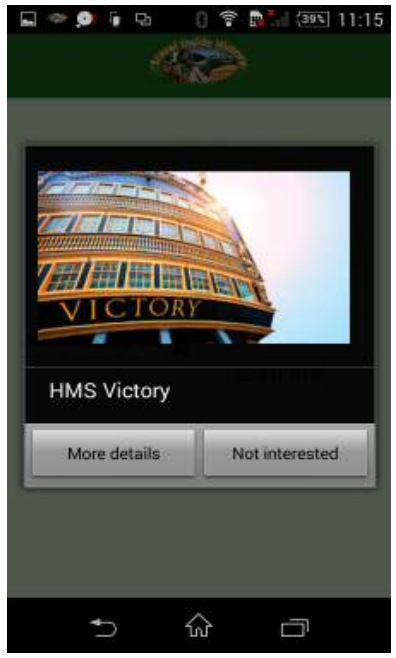

The viewing notification page

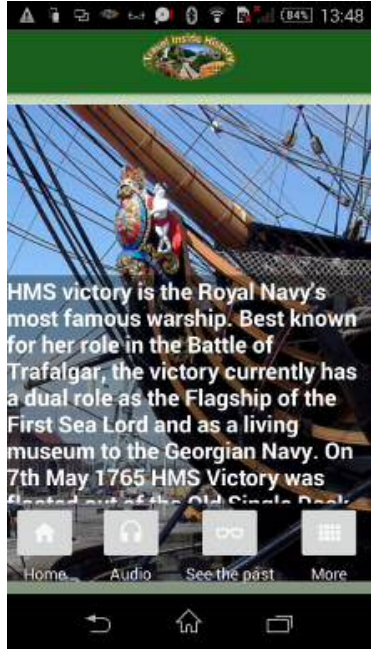

The attraction's page

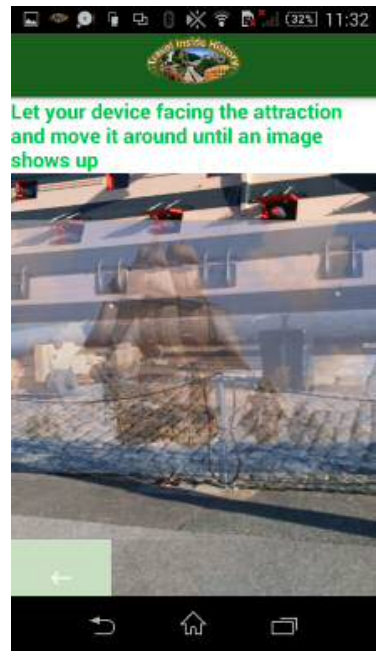

The "see it in the past" page

Fig. 1. The main pages of the prototype

Regarding the usefulness, the results indicate that all features provided by the app are useful as the mean is between 3.75 and 4.77. Participants liked receiving notifications based on location. Moreover, the results suggest that the audio explanation is the most popular information format amongst participants. Participants claimed that seeing attractions how appeared in the past is very interesting. Four participants used the smart eye glasses during the field study. Three out of four liked receiving notifications through the glasses and found it useful as it freed their hands from carrying the mobile device during the tour. One participants did not like it as she likes to see the attractions with her own eyes; however, it is a personnal decision; the device could be disabled if it is not needed (see Table II).

TABLE II. THE FEATURES RATING RESULTS

\begin{tabular}{|l|l|}
\hline \multicolumn{1}{|c|}{ Features } & Mean \\
\hline The audio explanations & 4.77 \\
\hline $\begin{array}{l}\text { The attraction's image within the } \\
\text { notification's dialogue }\end{array}$ & 4.69 \\
\hline Receiving notifications based on the location & 4.63 \\
\hline The text explanations & 4.58 \\
\hline $\begin{array}{l}\text { The attraction's image within the attraction's } \\
\text { page }\end{array}$ & 4.44 \\
\hline The attraction's image within the audio page & 4.40 \\
\hline The historical/documentary videos & 4.40 \\
\hline Seeing attractions how looked in the past & 4.15 \\
\hline Take a photo & 4.04 \\
\hline $\begin{array}{l}\text { Short messages giving feedback about tasks } \\
\text { process }\end{array}$ & 3.94 \\
\hline Error messages & 3.92 \\
\hline Receiving notifications on the glasses & 3.75 \\
\hline
\end{tabular}

With respect to the overall acceptance, the vast majority of participants liked the app and stated they are happy to use it and recommend it to friends. One participants only mentioned that he would not use it because he likes to read every label attached to the attractions.

The results of the interview suggest participants were very positive towards the app and found it very interesting and easy to use. However, they pointed out some challenges that they experienced during the tour such as: 1) Receiving notifications for the same attraction a couple of times when passing nearby; 2) Losing the current notification (i.e. when viewing a notification for a certain attraction and then move to another one, could not go back to the previous one); 3) Not very easy to see the old image constantly in the "see it in the past" feature as it is based on the location and it disappears once the device moves slightly; 4) The video needs an internet connection which was not very good at the Historic Dockyard.

Participants suggested a number of aspects to be included with the app to make it better such as: 1) add directions to take you to the attractions; 2) Provide the distance to the attraction that users get notified about from their current location; 3) Add a map with all attractions to make it easier to see what is near; 4) Provide an option to download the video; 5) Give users an opportunity to access the attraction's information whenever they want; 6) Add notifications about public services like cafes or toilets; 7) Consider the sorrounding environment in the design such as sunny or rainy as the sun makes it harder to see the screen sometimes; 8) Make the audio louder as it was not easy to listen to it in a group; however, using a headset splitter might solve this issue. 9) one participant suggested to have a list of the nearby attractions instead of receiving notifications based on the 
location. From her point of view users may not get close enough to an attraction to get a notification which may lead to missing an attraction. However, the main point of providing notifications based on the location is to support people to learn on-the-move while they are doing their daily activities.

The observational results indicate participants were comforble in using the app and also managed to use almost all the features easily. A number of challenges were noticed during the tour, which include:

- The quality of the network was poor at the site, which affected receiving notifications and playing videos.

- The surrounding environment, such as weather (sunny, windy or rainy) and noise, also affect the users experience.

- Visitors' level of knowledge regarding technology could obstruct the experience. Some participants had problems in using mobile devices in general, which made the use of the app slightly harder.

- The technical differences of the android devices in terms of operating system, as some devices show a good quality in picking locations and displaying messages more than others.

Altogether, the results of the interview and the observation are consistant which gives a level of confirmation of the findings.

\section{Designing The GUIDELINES}

The results of the current study indicate that receiving instant information regarding historical events based on location could have a good impact on enhancing learning from cultural heritage sites. The results provide an important insight of how people do interact with technology and contexts to learn about historical events that had happened in a certain site. The results show that the service is usable, useful and participants enjoyed the experience of using a smart learning environment at the site. However, some challenges were arisen, which were mentioned in the previous section. Both the positive and negative experiences could help enhancing learners' experiences at sites if they are taken into account when designing a learning environment. The study emphasizes a number of aspects that the results suggest which includes:

1) Personalizing the app: Participant would like the app to keep their route history to enable them to save the sites where they have been and to re-view the information when they want to.

2) Enhancing the interaction: participants stressed that adding more messages that explain how each service would work could make the interaction between the learners and the app more efficient. In addition, adding the distance for a certain interaction from the current location of learners would be easier for learners to find the attraction. Furthermore, including some services such as public services, and directions, and providing an option for downloading the video would make the experience better for learners.

3) Considering the sourounding environment: based on the results, taking the surrounding environment into consideration in designing the app could support enhancing the experience.

4) Considering the contexts: the results indicate that it is important to consider the contexts that the learning process occurs in terms of time, place, way of learning and, individuals or group.

5) Providing sufficient feedback regarding potential errors: the results highlight that it would be helpful for learners if the app gives sufficient feedback messages explaining the errors if they happened and how to fix them or find alternatives (e.g. downloading videos to watch it their own time rather that stay put in a place with good network quality at the site).

All the aforementioned aspects were taken into account to enhance the list of guidelines that was introduced in a previous study, which was designed based on two field studies using questionnaire and interview techniques with potential end-users [9]. Table III illustrats the design framework and examples of design elements, which both act as a guideline for designing smart and ubiquitous learning environment with respect to cultural heritage context.

TABLE III: A LIST OF GUIDELINES FOR DESIGNING MOBILE LOCATION-BASED LEARNING SERVICES

\begin{tabular}{|c|c|}
\hline Design framework & Examples of the design elements \\
\hline $\begin{array}{l}\text { Assist learners in } \\
\text { personalizing the service } \\
\text { based on their interests }\end{array}$ & $\begin{array}{l}\text { - Collect information about learners' interests by either (tracking learners' route and save } \\
\text { preferences, or ask learners to provide personal information regarding their interests when first } \\
\text { signing up, such as the favorite types of cultural heritage sites). } \\
\text { - Use learners' profile to give recommendations of services and activities } \\
\text { - Enables learners to choose their favorite aspects (e.g. color, learning preferences). } \\
\text { - Enable learners to save their favorites such as favorite sites to re-view them again in some other } \\
\text { time. }\end{array}$ \\
\hline $\begin{array}{l}\text { Assist learners to have a } \\
\text { full picture about stories } \\
\text { that a certain site has }\end{array}$ & $\begin{array}{l}\text { - Store historical information in a joint database that includes all attractions in which they are } \\
\text { sectioned under cities and regions }\end{array}$ \\
\hline
\end{tabular}




\begin{tabular}{|c|c|}
\hline Design framework & Examples of the design elements \\
\hline experienced back in time. & $\begin{array}{l}\text { Provide historical information about: } \\
\text { oHuman achievements at that time } \\
\text { oEvents that these sites have had experienced back in time } \\
\text { oStories behind these sites } \\
\text { oLife back in time } \\
\text { oHow sites used to appear in the past } \\
\text { oDevelopment of sites over time } \\
\text { oInformation about archaeology and excavation of these sites } \\
\text { oInteresting facts and funny stories about famous characters } \\
\text { - Provide useful information based on sites and locations (e.g. public service such as cafes, } \\
\text { transportations, ticket prices, the weather, etc.) }\end{array}$ \\
\hline $\begin{array}{l}\text { Assist learners to choose } \\
\text { the way that would like to } \\
\text { learn and make it an } \\
\text { enjoyable process }\end{array}$ & $\begin{array}{l}\text { - Provide different services and activities to support different types of learning such as: Geo- } \\
\text { cashing activities or games regarding historical events or characters). } \\
\text { - Provide various preferences of learning that suit different types of learners (e.g. stories, quizzes, } \\
\text { riddles etc.) }\end{array}$ \\
\hline $\begin{array}{l}\text { Assist learners in } \\
\text { organizing their visit to } \\
\text { cultural heritage and taking } \\
\text { a new learning } \\
\text { opportunity. }\end{array}$ & $\begin{array}{l}\text { - Provide a functionality that help motivate learners to visit cultural heritage site (e.g. a short } \\
\text { video talking about the significant achievements of humans that were achieved at a particular } \\
\text { site back in time) } \\
\text { - Provide a service that enable learners to look up useful information before hand to organize } \\
\text { their visit properly (e.g. the weather, tickets prices, transportation, etc.) } \\
\text { - Provide services that help receiving historical information based on the learner's current } \\
\text { location (e.g. a location-based tour, a map with nearby sites). }\end{array}$ \\
\hline $\begin{array}{l}\text { Assist learners to learn } \\
\text { while they are doing their } \\
\text { daily activities }\end{array}$ & $\begin{array}{l}\text { - Provide notifications to inform learners what is near in terms of cultural heritage when passing } \\
\text { nearby. } \\
\text { - Delivering instant information based on learners' physical location about cultural heritage sites. }\end{array}$ \\
\hline $\begin{array}{l}\text { Make the app usable and } \\
\text { easy to use for all learners }\end{array}$ & $\begin{array}{l}\text { - Provide multi-mode information format to deliver historical information (e.g. audio, video, text } \\
\text { and images). } \\
\text { - Provide different modes in terms of themes (day and night), tours (group, individual), etc. } \\
\text { - Allow learners to switch between modes easily. } \\
\text { - Allow learners to switch services off when they are not needed. } \\
\text { - Give a choice for learners to choose the level of interaction they want (e.g. provide a brief } \\
\text { description of information and add a "Read More" choice for more details, or provide a } \\
\text { scrollable text ) } \\
\text { - Adopt features that allow learners to see and experience life back in time (e.g. Utilize a } \\
\text { technology, such as augmented reality, that enables them to immerse in the atmosphere and } \\
\text { using their senses, for instance provide a simulation that enables learners to smell, listen, touch, } \\
\text { and imagine themselves taking part in life at that time). } \\
\text { - Provide feedback messages and explanation about how services work } \\
\text { - Provide an opportunity for learners to switch between services or abort them easily if they do } \\
\text { not want to proceed (e.g. give a "cancel" choice). } \\
\text { - Adopt a feature that saves learners' route, intelligently, and enable them to re-view the visited } \\
\text { attractions whenever they want. } \\
\text { - Provide a choice for learners to view information offline (e.g. a choice of downloading the } \\
\text { video, if there is any, to allow them watching it offline). } \\
\text { - Give learners a choice to save attractions to view them later if they do not want to view them at } \\
\text { a site (i.e. "Add it to my list"). } \\
\text { - Provide information that enables learners to find attractions easily (e.g. directions, orientation, } \\
\text { or/and distance ("you are near HMS M.33" the distance is } 50 \mathrm{~m} \text { west east). } \\
\text { - Allow learners to switch between devices easily (e.g. between wearable computing such as } \\
\text { Smart glasses and the mobile phone). }\end{array}$ \\
\hline Support learners to learn in & oport learners in sharing experiences in both contexts in and off the site \\
\hline
\end{tabular}




\begin{tabular}{|l|l|}
\hline \multicolumn{1}{|c|}{ Design framework } & \multicolumn{1}{c|}{ Examples of the design elements } \\
\hline $\begin{array}{l}\text { different contexts in terms } \\
\text { of times of the visit, the } \\
\text { type of the visit, type of } \\
\text { the visitors }\end{array}$ & $\begin{array}{l}\text { - Support learners in using services to experience sites individually or in a group. } \\
\text { - Support learners to re-view the attractions when they are off the site after the visit. }\end{array}$ \\
\hline $\begin{array}{l}\text { Support learners to share } \\
\text { knowledge and } \\
\text { experiences regardless of } \\
\text { their physical locations }\end{array}$ & $\begin{array}{l}\text { - Enable learners to create a network with each other to share thoughts and ideas while they are at } \\
\text { the site (i.e. online community). } \\
\text { Enable learners, who are at the site, to create a network that enables video calls with friends and } \\
\text { family who are not physically at the site to share with them the experience and get them to see } \\
\text { the site using the device's camera (distance visit). }\end{array}$ \\
\hline $\begin{array}{l}\text { Support learners to } \\
\text { overcome challenges that } \\
\text { might arise in using mobile } \\
\text { devices in outdoor settings }\end{array}$ & $\begin{array}{l}\text { - Handling the potential errors (e.g. no Wi-Fi connection is available, or poor network which affect } \\
\text { picking the location of attractions) by displaying error messages, or caution messages to make } \\
\text { them aware of what they are doing (e.g. "this service is using your data", "this service requires } \\
\text { an internet connection"). } \\
\text { - Help learners who are not familiar with technology to have a better experience using the app (e.g. } \\
\text { provide enough explanation about how each service works, make the error messages appear in } \\
\text { the middle of the screen with a bright color) }\end{array}$ \\
\hline
\end{tabular}

\section{CONCLUSION}

This paper has presented an empirical study to examine aspects of usability, usefulness and acceptance of a smart learning environment; SmartCity. SmartCity was designed to deliver instant information in outdoor cultural heritage contexts based on location with respect to cultural heritage sites. The study was carried out with adult end-users to obtain their perspective regarding their experience of using the app in the field. The results indicate that SmartCity is easy to use and it is a useful tool for learning from cultural heritage sites. The current version of the guidelines was set out based on this study for designing such services. Further work is needed to enhance the system based on the current version of the guideline. Additionally, we will include more design elements with SmartCity, such as socialisation and communication features. Moreover, we will extend the "see it in the past" feature so that it can be viewed through the smart eye glasses.

\section{REFERENCES}

[1] M. Sharples, I. Arnedillo-Sánchez, M. Milrad, and G. Vavoula, Mobile learning: Springer, 2009.

[2] S. Benford, "Future location-based experiences," JISC: Technology \& Standards Watch, 2005.

[3] H. Ogata, and Y. Yano, "Context-aware support for computer-supported ubiquitous learning.", Proceedings of the 2nd IEEE International Workshop on Wireless and Mobile Technologies in Education, 2004. pp. 27-34.

[4] H. Candello, "Developing Principles for Outdoor Mobile Multimedia Guide in Culture Heritage Settings.", procceedings of ACM, MoileHCI'09, 2009.

[5] C. Van Aart, B. Wielinga, and W. R. Van Hage, "Mobile cultural heritage guide: location-aware semantic search," Knowledge Engineering and Management by the Masses, pp. 257-271: Springer, 2010.

[6] Y. Poria, R. Butler, and D. Airey, "Links between tourists, heritage, and reasons for visiting heritage sites," Journal of Travel Research, vol. 43, no. 1, pp. 19-28, 2004.

[7] A. N. Oppenheim, Questionnaire design, interviewing and attitude measurement: Bloomsbury Publishing, 1992.
[8] E. Kangas, and T. Kinnuen, "Applying User-Centred Design to Mobile Application Development," ACM, vol. 48, 2005.

[9] A. Alkhafaji, S. Fallahkhair, M. Cocea, and J. Crellin, "Developing a Theoretical Framework for Designing Smart and Ubiquitous Learning Environments based on Mobile and Wearable Technologies," in Submitted to be published 2017.

[10] A. Damala, P. Cubaud, A. Bationo, P. Houlier, and I. Marchal, "Bridging the gap between the digital and the physical: design and evaluation of a mobile augmented reality guide for the museum visit.",ACM Proceedings of the 3rd international conference on Digital Interactive Media in Entertainment and Arts, 2008. pp. 120-127.

[11] M. Angelaccio, A. Basili, and B. Buttarazzi, "Using Geo-business Intelligence and Social Integration for Smart Tourism Cultural Heritage Platforms.",peocceedings of IEEE 21st International Workshop on Enabling Technologies: Infrastructure for Collaborative Enterprises (WETICE), 2012. pp. 196-199.

[12] A.-C. Haugstvedt, and J. Krogstie, "Mobile augmented reality for cultural heritage: A technology acceptance study.", procceedings of IEEE International Symposium on Mixed and Augmented Reality (ISMAR), 2012. pp. 247-255.

[13] V. Vlahakis, J. Karigiannis, M. Tsotros, M. Gounaris, L. Almeida, D. Stricker, T. Gleue, I. T. Christou, R. Carlucci, and N. Ioannidis, "Archeoguide: first results of an augmented reality, mobile computing system in cultural heritage sites.", proccedings of Virtual Reality, Archaeology, and Cultural Heritage, 2001. pp. 131-140.

[14] G. Takacs, V. Chandrasekhar, N. Gelfand, Y. Xiong, W.-C. Chen, T. Bismpigiannis, R. Grzeszczuk, K. Pulli, and B. Girod, "Outdoors augmented reality on mobile phone using loxel-based visual feature organization.", Proceedings of the 1st ACM international conference on Multimedia information retrieval, 2008. pp. 427-434.

[15] Y. Suh, C. Shin, W. Woo, S. Dow, and B. MacIntyre, "Enhancing and evaluating users' social experience with a mobile phone guide applied to cultural heritage," Personal and Ubiquitous Computing, vol. 15, no. 6, pp. 649-665, 2010.

[16] G. Gediga, K.-C. Hamborg, and I. Düntsch, "The IsoMetrics usability inventory: an operationalization of ISO 9241-10 supporting summative and formative evaluation of software systems," Behaviour \& Information Technology, vol. 18, no. 3, pp. 151-164, 1999. 